Revista Destaques Acadêmicos, Lajeado, v. 13, n. 2, 2021. ISSN 2176-3070

DOI: http://dx.doi.org/10.22410/issn.2176-3070.v13i2a2021.2897

http://www.univates.br/revistas

\title{
MEIO AMBIENTE, CRISTIANISMO E ECOTEOLOGIA: UMA ANÁLISE INTERDISCIPLINAR
}

\author{
Paulo Jonas dos Santos Júnior ${ }^{1}$, Pedro Henrique Caetano Figueira², \\ Silvana Duarte Gonçalves dos Santos ${ }^{3}$
}

\begin{abstract}
Resumo: $\mathrm{O}$ artigo tem por finalidade esboçar os paradigmas de interpretação de mundo da Ecoteologia; desta forma, fez-se necessário uma contextualização da história do cristianismo, para assim se compreender a estrutura crucial da religiosidade cristã. É sabido que as preocupações com o meio ambiente tem ganhado um destacado lugar no meio científico e acadêmico, porém por vezes essa preocupação não é vista no ambiente religioso. Desse modo este trabalho busca analisar como assuntos relacionados ao meio ambiente são tratados no âmbito da teologia cristã; dessa forma, para um melhor entendimento sobre a formação da doutrina e da cultura cristã, foi realizado um levantamento de caráter historiográfico. Por fim, foi possível constatar que apesar da temática ambiental ter sido tratada como de menor importância durante muito tempo por parte de várias áreas das Ciências Humanas e Sociais, ultimamente esse assunto
\end{abstract}

1 Pós-Doutorando pela Universidade Estadual Paulista - UNESP, com pesquisa sobre Sustentabilidade, Cultura e Desenvolvimento Urbano; Doutor em Planejamento Regional e Gestão da Cidade pela Universidade Cândido Mendes (UCAM-Campos), com pesquisa sobre a influência do Pentecostalismo na urbanização brasileira; Mestre em Ciências das Religiões pela Faculdade Unida de Vitória (UNIDA); Pós-graduado em História e Cultura no Brasil pela Universidade Estácio de Sá (UNESA); Pós-graduado em Tutoria em Educação a Distância e Docência do Ensino Superior (ICETEC); Pós-graduado em Filosofia e Sociologia (ICETEC); Pós-graduado em Metodologia de Ensino Religioso e Artes (ICETEC); Pós-graduado em História e Filosofia (UNINTER); Licenciado em História pelo Instituto Superior de Educação Ibituruna (ISEIB); Licenciado em Geografia pelo Centro Universitário de Venda Nova do Imigrante (UNI); Bacharel em Teologia pela Faculdade de Ciências e Tecnologia da CGADB (FAECAD); Formação em Psicanálise Clínica (FATEB); Formação Musical pelo Conservatório Brasileiro de Música (CBM). Professor do Centro Universitário São José de Itaperuna-RJ. Contato: paulojsjunior@hotmail.com.

2 Graduado em História pelo Centro Universitário São José de Itaperuna (UNIFSJ). Contato: pedrocaetano445@gmail.com

3 Especialista em Língua Portuguesa (FAFITA); Especialista em Psicopedagogia (UCB); Graduada em Letras (FAFITA); Graduada em Teologia (UNIDA). Contato: silvanadgsantos@hotmail.com. 
tem ganhado espaço nas discussões acadêmicas e possibilitado a consolidação de novas perspectivas, como é o caso da própria Ecoteologia.

Palavras-chave: Ecoteologia; Meio Ambiente; Teologia; Sustentabilidade; Interdisciplinaridade.

\section{I - INTRODUÇÃO}

Desde o início de sua história no planeta o ser humano busca compreender a dinâmica da natureza; essa questão, inclusive, embasou os pensadores présocráticos na estruturação do pensamento crítico do qual originou a Filosofia. $\mathrm{Na}$ antiguidade, a relação do homem para com o meio ambiente era cercada de crenças e mitos, uma vez que a humanidade atribuía aos deuses e a outros diversos seres divinos a autoria dos acontecimentos dos fenômenos naturais. Igualmente, durante a Idade Média, a fé era o guia do ser humano na busca da compreensão dos acontecimentos comuns do cotidiano, como chuva, sol, doença, dentre outros.

Na Idade Moderna, porém, algumas descobertas científicas colaboraram para que a compreensão acerca da natureza se afastasse da explicação mitológica ou religiosa. Entretanto foi na Idade Contemporânea, já na segunda metade do século XX, que a responsabilidade com o meio ambiente começou a ser tratada com seriedade por parte da sociedade.

Dessa maneira, este trabalho busca compreender a relação entre o cristianismo e o meio ambiente sob um foco interdisciplinar, e principalmente investigar como a Ecoteologia tem contribuído com os estudos acadêmicos. A metodologia utilizada para este estudo é a de revisão bibliográfica, com consultas realizadas em publicações especializadas e que discutem o assunto; essa metodologia foi adotada, uma vez que possibilita trabalhar com dados mais acurados e atualizados.

\section{II - BREVE HISTÓRICO DO CRISTIANISMO}

A história do Cristianismo se confunde muitas das vezes com a história europeia. De fato a relação entre a religião cristã e os fatos históricos ocorridos na Europa tem uma relação íntima. O Cristianismo surgiu em um contexto de expansões territoriais do Império Romano ${ }^{4}$, assim como em um momento importante de trocas culturais entre o oriente e ocidente ${ }^{5}$ (FUNARI, 2013).

4 Considerado o maior Império que já existiu no planeta, o Império Romano em seu período máximo abarcou geograficamente o norte da África, toda a Europa e o Oriente Médio. No Oriente Médio, o Império Romano influenciou o judaísmo assim como sofreu influências da cultura judaica (MATA, 2010);

5 A nomenclatura oriente e ocidente tratada neste texto se refere à divisão realizada por Teodósio no ano 395 (SANTOS JÚNIOR et al., 2019). 
Nesse contexto político e social, nasceu Jesus ${ }^{6}$, um judeu que não se conformou com os problemas sociais enfrentados pela população mais pobre. A partir da sua segunda década de vida, Jesus começou a pregar para os povos economicamente menos favorecidos, em sua maioria para os judeus. Apesar de os avanços científicos, a vida de Jesus ainda é uma incógnita, pois o que se sabe sobre ele se estrutura, principalmente, a partir de suas pregações na fase adulta. Acredita-se que Jesus foi condenado e morreu crucificado, e esse fato foi determinante para o início do Cristianismo; pois a partir de sua morte, seus apóstolos começaram a escrever os ensinamentos dele recebidos e, assim, reproduzir a visão de mundo e de espiritualidade de Jesus (FUNARI, 2013).

Nesse momento, o Cristianismo passou pelo que os historiadores chamam de "Cristianismo Primitivo", em que suas reuniões aconteciam às escondidas, já que a fé cristã ainda era considerada uma religião clandestina ${ }^{7}$. Isso mudou a partir da conversão do imperador romano Constantino ${ }^{8}$ ao cristianismo, o que se firmou como um marco para a Igreja. Sobre isso, Funari (2013, p.131) esclarece:

Quando o imperador romano Constantino, no século IV d.C., converteu-se ao cristianismo, já havia cristãos em quase todo o mundo romano, ainda que fossem uma minoria. Os cristãos já possuíam uma organização, a Igreja Cristã, com uma estrutura hierárquica bem definida. Particular destaque na Igreja tinham os bispos, que controlavam a vida espiritual dos fiéis em suas áreas de atuação, o que faziam tanto por meio de pregações, como da ação dos sacerdotes.

Constantino conseguiu se estruturar no poder romano embarcando na força do Cristianismo, e logo após a sua conversão, nomeou o Império Romano como Império Romano Cristão. Quando Constantino se converteu ao Cristianismo, a religião começou a ter solo fértil para reproduzir e transformarse. Nesse contexto, deixou de ser apenas uma seita clandestina e começou a ganhar corpo como a maior religião do Império Romano. Com o imperador

6 Jesus foi um judeu que durante sua vida caminhou por diferentes povos pregando o que ele chamou de "Boa Nova". Com muitas críticas ao sistema político e ao judaísmo, foi preso, torturado e morto pelo Império Romano (SANTOS JÚNIOR et al., 2019).

7 A fé cristã não era uma religiosidade aprovada pelo Estado, e dessa forma as reuniões eram restritas e escondidas (GOMBRICH, 2000).

8 Flávio Valério Aurélio Constantino, viveu entre 272 d.C. a 337 d.C. Foi um Imperador Romano de suma importância para o Cristianismo, pois, com ele a religiosidade teve abertura para difundir seus ensinamentos e doutrinas. Com Constantino o Império Romano passa de politeísta para uma religião monoteísta, crendo na ressurreição de Jesus Cristo (GOMBRICH, 2000). 
Teodósio9 , a Igreja Cristã passou a ter uma sólida hierarquia, com bispos e sacerdotes; igualmente, o cristianismo começou a ter uma grande influência nas decisões políticas e a possuir inúmeros privilégios. De fato esse momento foi muito importante para história da Igreja, o que a possibilitou se tornar não apenas uma simples instituição religiosa, mas, também, o próprio Estado (COLLINS; PRICE, 2000).

As preocupações da Igreja Cristã mudaram conforme a passagem dos séculos. Na idade antiga, a Igreja preocupava-se com sua sobrevivência, com a escrita da Boa Nova e com as conversões. Na Idade Média ${ }^{10}$, porém, quando atingiu o poder político, a Igreja passou a se ocupar com questões relacionadas à política. As ações do Cristianismo no período medieval foram de forte viés social entre os governos da época, e se moveram ao encontro dos interesses e das ambições para o monopólio cultural. No mesmo período, porém, duas grandes cisões mexeram na estrutura da Igreja Cristã; a primeira, em 1054, quando a Igreja Oriental de separou da Igreja Ocidental; e a segunda em 1517, de maior repercussão, ficou conhecida como Reforma Protestante (COLLINS; PRICE, 2000).

O contexto da consolidação da Igreja Cristã acompanhou a história política do Império Romano, havia neste período preocupações mais universal, pois a Igreja era unificada e existia um diálogo mais circunvizinho com a centralidade do poder nas mãos de um líder e com uma hierarquia estruturada ${ }^{11}$; porém a diferença cultural entre a ala ocidental, influenciada por Roma, e a ala oriental, sob influência da cultura árabe, eram eminentes. Uma série de conflitos doutrinais assolava a Igreja, e assim surgiam várias discordâncias que foram corroendo a comunhão interna (MATA, 2010). Nessa perspectiva, cabe observar que o Cisma:

Foi algo que aconteceu gradativamente, como resultado de um processo longo e complicado, que começou muito antes do século $\mathrm{XI}$ e que só terminou um pouco depois daquela época. Influências diversas contribuíram para tal. $\mathrm{O}$ cisma condicionou-se a fatores culturais, políticos, e econômicos. No entanto sua causa fundamental não foi secular, mas sim teológica. Em última análise, foi por causa de assuntos doutrinais que o oriente e o ocidente se desentenderam (ECCLESIA, 2020).

9 Importante Imperador Romano que viveu durante os anos 347 d.C. a 395 d.C. (GOMBRICH, 2000).

10 Período da História Europeia que compreende entre a queda do Império Romano do Ocidente e se estende até a tomada de Constantinopla pelos turcos otomanos (GOMBRICH, 2009).

11 Bispos, Cardeais e Sacerdotes (MATA, 2010). 
Torna-se mister refletir que o distanciamento existente entre a ala Ocidental e a Oriental se intensificou com o passar do tempo; a fundação da segunda capital do Império ${ }^{12}$, por exemplo, tirou o foco do oriente para Roma, e assim os dois polos se afastaram ainda mais. Outro fator que agravou a falta de diálogo entre oriente e ocidente é a expansão do Islã ${ }^{13}$, pois:

O mediterrâneo, que outrora havia sido chamado de Mare Nostrum pelos romanos, passava agora, em grande parte, ao controle dos árabes. Os contatos culturais e econômicos entre o oeste e o leste do mediterrâneo nunca cessaram completamente, mas se tornaram bem mais difíceis (Ecclesia, 2020).

A série de medidas políticas adotadas por Roma desencadeou ao oriente muitos questionamentos e diversas insatisfações. Com a queda do Império Romano do Ocidente em 476 d.C., a Igreja Católica do Ocidente foi influenciada pela cultura dos que invadiram Roma, portanto os francos ${ }^{14}$ transmitiram vários valores para a vida dos ocidentais, e a Igreja, como instituição, também absorveu algumas essências da cultura dos invasores. Em meio a tantas divergências, a ala oriental da Igreja Católica viu com profunda estranheza a coroação de Carlos Magno, um "bárbaro" na concepção oriental. Diante disso:

Desligado de Bizâncio, o ocidente tratou de estabelecer o seu próprio Império "Romano." No dia de natal do ano de 800, o Papa coroou Carlos Magno, rei dos francos, imperador. Carlos Magno procurou, em vão, o reconhecimento do imperador de Bizâncio. Os bizantinos, que ainda acreditavam no princípio da unidade do império, viam Carlos Magno como um intruso e sua coroação feita pelo Papa, como um ato cismático dentro do império. A criação de um Império romano cristão no ocidente, ao invés de unir a Europa, serviu tão somente para separar ainda mais o Oriente e o Ocidente (ECCLESIA, 2020).

Contudo foram questões doutrinárias que agravaram a crise entre a ala oriental e a ala ocidental da igreja cristã. Discussões sobre a infalibilidade papal ${ }^{15}$

12 Constantinopla foi uma cidade crucial para o desenvolvimento do Império Bizantino. Foi construída por Constantino para auxiliar na administração do Império Romano (GOMBRICH, 2000).

13 Religião monoteísta que tem como Deus, Alá, e seu principal profeta Maomé (GOMBRICH, 2009).

14 Povos vizinhos ao Império Romano de cultura germânica. Estes povos eram considerados pelos romanos como povos "bárbaros" e foram eles que invadiram o Império Romano contribuindo para sua queda (MATA, 2010).

15 Doutrina católica ocidental que preza por um líder infalível (LENZENWEGER et al., 2006). 
e a trindade ${ }^{16}$ tornaram o ocidente e o oriente indialogável e a situação se tornou insustentável em 1054, com as decisões do Papa Leão IX ${ }^{17}$ e do Patriarca Miguel Cerulárius $^{18}$. O Patriarca do oriente fez uma estruturada campanha contra a Igreja Latina, fundamentando de forma doutrinária e teológica as críticas ao ocidente. Papa Leão IX decidiu então excomungar a Igreja Oriental, e, como resposta, o patriarca decidiu excomungar a Igreja Ocidental (ECCLESIA, 2020).

Após o Cisma, a Igreja Católica Apostólica Romana seguiu sua linha cultural ocidental e durante a Idade Média veio a se tornar a instituição mais importante da Europa, com atuações políticas na manutenção de monarquias, na ordem feudal e também nas cidades, as quais neste momento se encontravam infestadas de descendentes germânicos e francos (LE GOFF, 2005).

Mais tarde, no século XVI, a Reforma Protestante teve como resultado uma profunda mudança no cerne da Igreja Católica, uma vez que esse acontecimento possibilitou o surgimento de novas ordens sociais, econômicas e influenciou até mesmo na filosofia moderna. Apoiada nas 95 teses de Martinho Lutero $^{19}$, esse acontecimento foi o estopim para algo que já estava pairando sobre a Europa, o descontentamento com as medidas adotadas pela Igreja do Ocidente por séculos. Esse evento foi muito significativo e cabe esclarecer que:

Tais teses foram abraçadas por governantes e líderes religiosos de diversos países da Europa, como Alemanha, Suíça, França e Reino Unido; o que resultou no rompimento da unidade da igreja cristã ocidental originando os denominados cristãos católicos, seguidores de Roma e do papa, e os cristãos protestantes, seguidores das teses de Lutero (SANTOS JÚNIOR; ROSA, 2016, p.237)

Desta forma, a Reforma Protestante significou não somente mais uma ruptura no Cristianismo, mas também um brusco desmembramento entre Igreja e Estado na Europa. Nesta perspectiva, porém, cabe ressaltar que a História da

16 Doutrina pilar da Igreja Católica que fala sobre três pessoas em apenas uma. Pai, Filho e Espírito Santo clamados de forma unida representa o que os cristãos católicos chamam de “Mistério da Fé" (LENZENWEGER et al., 2006).

17 Foi o $152^{\circ}$ sucessor do trono papal e ficou conhecido por vivenciar um dos maiores cismas religiosos da História das Religiões (GOMBRICH, 2009).

18 Foi o chefe da Igreja Católica Ortodoxa no período 1043 d.C. a 1054 d.C. Ficou conhecido pelo fatídico acontecimento que racharia a Igreja Cristã em duas, Igreja Católica Romana e Igreja Católica Ortodoxa (LENZENWEGER et al., 2006).

19 Monge Agostiniano mentor das 95 teses. Viveu entre 1483 d.C. e 1556 d.C. Ficou reconhecido por ter dado o estopim do cisma do catolicismo moderno (SANTOS JÚNIOR; ROSA, 2016). 
Igreja Cristã foi construída por eventos como: cismas, disputas políticas, brigas pelo poder, e uma imensa pluralidade e divergências teológicas (MATA, 2010).

\section{III - MEIO AMBIENTE E SUSTENTABILIDADE}

A temática da sustentabilidade tem ganhado cada vez mais espaços nas discussões acadêmicas ${ }^{20}$. Desde a década de 1990, principalmente, assuntos ligados ao meio ambiente têm sido pesquisados em disciplinas das mais diversificadas áreas do conhecimento humano ${ }^{21}$. Cabe ressaltar que durante muito tempo questões correlacionadas ao meio ambiente eram encaradas como sendo de responsabilidade das Ciências Biológicas ou então da Engenharia Ambiental (SILVA et al., 2020); porém nas últimas décadas, a questão começou a ganhar espaços em outras áreas, e, consequentemente, estudiosos das ciências humanas e sociais passaram a se dedicar a essa temática (FERREIRA et al., 2019).

É importante observar que a questão ambiental está diretamente relacionada à vida humana. Os impactos ambientais causados pelas ações do ser humano têm sido alvo de questionamentos pela sociedade, e, dessa maneira, estudos recentes têm buscado a reduzir tais impactos.

$\mathrm{Na}$ área das Ciências Biológicas e da Natureza, a Biologia, a Química, a Física, a Geografia e outras do mesmo segmento, buscam, de maneira integrada, compreender o funcionamento do Planeta e levantar dados que possam servir de base para as outras áreas (SILVA et al., 2020). É indispensável que esses estudos sejam realizados com frequência para que ocorra uma atualização periódica da situação do planeta terra. Nessa mesma perspectiva, é importante salientar que as ciências ligadas à natureza podem contribuir de maneira significativa com questões diretamente ligadas ao meio ambiente e à preservação da vida; como no caso de estudos que se relacionam com as calotas polares $^{22}$, preservações de florestas, extração de minérios ${ }^{23}$, preservação da

20 Estudos científicos recentes, principalmente na área das ciências humanas e da natureza, têm se preocupado com a temática (SILVA et al, 2020).

21 A partir da década de 1990, várias ciências se debruçam sobre os problemas ambientais e as consequências para o futuro. A Física, Geografia, Filosofia, Biologia e até mesmo a Teologia intensificaram suas pesquisas acerca do tema (FERREIRA et al, 2019).

22 As calotas polares são grandes blocos de gelo que se formam nos polos da Terra e possuem uma importante função para o equilíbrio do Planeta (TOWNSEND; BEGON; HARPER, 2010).

23 As atividades ligadas ao extrativismo mineral causa poluição na água, no ar e profundos danos ao meio ambiente (TOWNSEND; BEGON; HARPER, 2010) 
flora e da fauna, conservação de biomas, estudos relacionados com a camada de ozônio ${ }^{24}$, dentre outros (JACOBI, 2003) .

A área da engenharia também exerce um importante papel para a preservação da natureza. Ao elaborar uma obra, um engenheiro pode, por exemplo, escolher materiais que prezam pelo meio ambiente. Cabe ressaltar que a própria estrutura de uma construção pode gerar economia de energia elétrica, conforto térmico, melhor utilização do espaço e até mesmo reutilização de água ${ }^{25}$. As engenharias também possuem áreas de estudo que podem contribuir de modo relevante para que no futuro a sociedade possa viver de forma mais ecológica e sustentável, como no caso da engenharia ambiental, engenharia mecânica, engenharia elétrica, engenharia de materiais, dentre outras (FANTINATTI; ZUFFO; ARGOLLO, 2015).

Igualmente, as Ciências Sociais Aplicadas têm se dedicado ao estudo da sustentabilidade. Cursos tradicionais, como o Direito, por exemplo, tem cada vez mais se dedicado a compreender as questões ambientais e como a sociedade pode se desenvolver economicamente sem agredir a natureza. $\mathrm{O}$ interesse pelo estudo de Planejamento Urbano e Regional, também, tem sido cada vez maior, em especial com as questões relacionadas aos problemas típicos das cidades ${ }^{26}$, como política de ocupação do solo, saneamento básico, acesso aos bens e serviços públicos, tratamento de água, estudos de transportes urbanos, dentre outros (JACOBI, 2003).

Da mesma forma, os estudos das Ciências Humanas são relevantes para o desenvolvimento sustentável da sociedade. A área humana é muito ligada com a educação escolar, o que pode contribuir para que desde a tenra infância o ser humano possa compreender a importância da sustentabilidade. Algumas disciplinas das Ciências Humanas, têm se dedicado ao estudo e compreensão das questões ambientais e a consequente relação dessas com a vida humana; dentre elas, pode se destacar a Teologia, que através de uma abordagem Ecoteológica ${ }^{27}$ tem contribuído para o avanço da área (FERREIRA et al., 2019).

24 A camada de ozônio é uma cobertura de gás que o Planeta possui, e que é indispensável para o equilíbrio da vida na Terra (TOWNSEND; BEGON; HARPER, 2010)

25 Nos últimos anos, a busca pela utilização de técnicas sustentáveis tem sido constante nas engenharias e na arquitetura, como por exemplo: o uso de telhas que permitem a passagem da luz solar, aproveitamento de materiais de demolição, reúso de água, dentre outras (FANTINATTI; ZUFFO; ARGOLLO, 2015).

26 Os estudos urbanos são indispensáveis para a melhoria da qualidade de vida do ser humano. De caráter interdisciplinar, a busca pela compreensão das dinâmicas urbanas tem sido essencial para a produção de cidades mais saudáveis e sustentáveis (BOFF, 2017).

27 Recentemente, a Ecoteologia tem ganhado visibilidade no espaço acadêmico. Essa abordagem busca refletir sobre a vida humana e como esse pode viver de forma mais sustentável (BOFF, 2017). 


\section{IV - TEOLOGIA CRISTÃ, ECOTEOLOGIA E MEIO AMBIENTE}

$\mathrm{Na}$ concepção teológica cristã contemporânea, foi fundamental a preocupação com uma nova forma de ver o mundo, colocando na centralidade do debate religioso, o que os cristãos chamam de Casa Comum ${ }^{28}$. Um dos entusiastas da Ecoteologia é o teólogo brasileiro Leonardo Boff. Sua vasta obra convida o cristão a refletir sobre as influências de sua ação no mundo, na natureza como um todo. Essa nova perspectiva se mostra muito paradoxal quando olhamos para a história das ações de influências da cristandade. Agora, de caráter mais conciliatório, a centralidade do debate é o futuro do planeta. A nova realidade no pensamento cristão tem diferentes correntes e muitos debates, porém mostra-se pertinente em todos os aspectos, já que estamos abordando a história da maior religião do planeta, a qual comandou o pensamento europeu por mais de um milênio (BOFF, 2004).

O enfrentamento sobre as raízes dos problemas ambientais se aflora em 1972 com o Clube de Roma $^{29}$, esse clube foi um diálogo franco entre pessoas influentes no mundo capitalista, todos preocupados com o desenrolar da crise ambiental. Os abusos das ações humanas começam a surtir fortes respostas do planeta. O sistema capitalista se adapta, tem facilidade em dialogar com culturas, tem uma estruturação que permite longevidade. A lógica é baseada no lucro, a alta produtividade para prazer imediato, sem preocupações do que pode ocorrer em longo prazo. O raciocínio geralmente é pautado no individualismo, e, assim, não existe neste sistema uma preocupação mútua com o coletivo, tampouco com as gerações futuras (BOFF, 2004).

O meio ambiente fica refém desta relação promíscua entre os donos dos meios de produção e o lucro imediatista e individual. Pessoa $(2019$, p.44) esclarece que:

Essas crises no meio ambiente são resultado de uma sociedade consumista e limitada ao pensar desenvolvimento apenas no quesito econômico, ou seja, maior ganho de dinheiro, na quantidade de produção através de máquinas modernas e no aumento de consumo de produtos industrializados por uma sociedade conduzida por um sistema capitalista que não valoriza o cuidado com o meio ambiente.

É necessário, neste contexto, as sociedades compreenderem que não é o vínculo de produção que irá alavancar o homem, pois este papel fundamental quem oferece é o meio ambiente, não é difícil relacionar essa linha de raciocínio.

28 Um termo utilizado com frequência na Ecoteologia, uma vez que nesta disciplina, há uma busca de refletir sobre o Planeta Terra como uma casa de todos os seres vivos (BOFF, 2004).

29 ONG (Organização Não Governamental) que atua sobre diversos aspectos. Na década de 1970 ganhou notoriedade por voltar-se para os problemas ambientais que o planeta estava enfrentando. 
Quem oferece a matéria prima é a natureza, a mão de obra é a natureza, o vínculo social tem como base o local geográfico onde vivem, portanto é uma linha tênue de equilíbrio fundamental. Sem o chão que pisamos não existe nenhum meio de produção (BOFF, 2004).

Neste momento crucial, é fundamental compreender que as religiões têm uma missão fundamental na derrocada deste paradigma, a ecologia e a teologia, de forma interdisciplinar entendem-se bem e necessitam serem postos à prática. Pessoa $(2019$, p. 51) contribui:

Em muitas religiões a relação da pessoa humana com o meio ambiente tem como pressuposto a ideia de que a natureza é uma manifestação da divindade e, por isso, precisa ser respeitada, pois com base nos estudos da etnologia, da antropologia, arqueologia, historiadores e cientistas da religião, a relação natureza e humanidade é universal, assim como a existência de deuses em todos os povos que habitam ou habitaram o mundo.

As comunidades de fé entendem que existe uma relação íntima entre o divino e o meio ambiente, pois as revelações da religião podem se manifestar através dos fenômenos da natureza. Desta forma é relevante que as religiões trabalhem, de forma concisa e elaborada, a consciência do "Deus que ama seu povo, mas que ama toda sua criação; é dele o monopólio do poder, e se aqui o ser humano produz, é porque Ele permitiu" ${ }^{\prime 30}$. Essa relação entre a teologia cristã e o meio ambiente foi fundamentalmente relevante para que este novo debate e enfrentamento perpetuem por séculos de forma ecumênica ${ }^{31}$ e conciliar.

\section{V - CONSIDERAÇÕES FINAIS}

Uma das maiores preocupações na atualidade é o cuidado com o planeta. É sabido que durante muitos anos o ser humano viveu como se os recursos naturais fossem ilimitados. Dessa maneira, a queima de combustíveis fósseis, a poluição dos rios e fontes de água doce, a derrubada de árvores para a utilização da madeira, dentre outas ações têm causado graves prejuízos para o Planeta Terra. Cabe ressaltar que o reflexo desse desequilíbrio ambiental compromete a saúde do ser humano.

30 Essa consciência judaico-cristã perpetua a muitos séculos, porém, esta preocupação tem influenciado em decisões mais fundamentadas. Um exemplo muito prático é a Laudato $\mathrm{Si}$, carta encíclica de Papa Francisco e posteriormente o Sínodo da Amazônia, que tratou de temas sensíveis aos problemas enfrentados pelos habitantes da floresta e sua biodiversidade. Também foi tratado no Sínodo os problemas enfrentados por padres e clérigos para a catequização (ESTRADA, 2018).

$31 \mathrm{O}$ ecumenismo ganhou ainda mais força após o Concílio Vaticano II, onde teve grande repercussão e uma aproximação com várias vertentes cristãs, principalmente a linha Protestante (ESTRADA, 2018). 
Dessa forma, a Teologia tem buscado conciliar a espiritualidade com a sustentabilidade, de forma a alcançar um equilíbrio entre a fé e a utilização dos recursos naturais disponíveis no Planeta.

Por fim, cabe observar que o desenvolvimento sustentável pode estar presente nas discussões das mais diversificadas áreas do conhecimento humano, uma vez que o estudo multidisciplinar pode contribuir para que as pesquisas sejam mais eficientes e precisas.

\section{REFERÊNCIAS}

BOFF, Leonardo. Ecologia: Grito da Terra, Grito dos pobres. Rio de Janeiro: Sextante, 2004.

BOFF, Leonardo. Sustentabilidade: o que é - o que não é. Petrópolis: Editora Vozes, 2016.

COLLINS, Michael; PRICE, Matthew A. História do Cristianismo: 2000 anos de fé. São Paulo: Loyola, 2000.

Ecclesia. Da desavença ao cisma: 858 - 1204. Disponível em: http:/ / www.ecclesia. com.br/biblioteca/igreja_ortodoxa/a_igreja_ortodoxa_historia8.html. Acesso em: 23 de mar. De 2021.

ESTRADA, Eduardo Moyano. Un ensayo sobre la Laudato si' y su contribución a la conciencia ambiental. Revista de Fomento Social, [S.L.], p. 441-456, 31 dez. 2018. Universidad Loyola Andalucia. http://dx.doi.org/10.32418/rfs.2019.291-292.1512.

FANTINATTI, Pedro Augusto Pinheiro; ZUFFO, Antonio Carlos; ARGOLLO, André Munhoz de. Indicadores de Sustentabilidade em Engenharia: como desenvolver. São Paulo: Elsevier, 2015.

FERREIRA, Lucimary da Silva Pedro et al. A INTERDISCIPLINARIDADE NA EDUCAÇÃO AMBIENTAL. Revista Transformar, Itaperuna-Rj, v. 13, n. 1, p. 19-35, jul. 2019.

Funari, Pedro Paulo. Grécia e Roma. 5 ed. São Paulo: Contexto, 2013.

GOMBRICH, Ernst. A História da Arte. São Paulo: Saraiva, 2000.

JACOBI, Pedro. Educação ambiental, cidadania e sustentabilidade. Cadernos de Pesquisa, [S.L.], n. 118, p. 189-206, mar. 2003. FapUNIFESP (SciELO). http:/ /dx.doi. org/10.1590/s0100-15742003000100008.

LE GOFF, Jacques. Em busca da Idade Média. Rio de Janeiro: Civilização Brasileira, 2005.

MATA, Sérgio da. História e Religião. Belo Horizonte: Autêntica Editora, 2010. 
PESSOA, Jimmy Barbosa. UMA REFLEXÃO SOBRE O PENSAR E ANUNCIAR A SUSTENTABILIDADE NO CRISTIANISMO. Último Andar. São Paulo. v. 23. n. 33. p. 42 - 56. 2019. Disponível em: https://ken.pucsp.br/index.php/ultimoandar/ article/view/43613. Acesso em: 24 de març. De 2021.

SANTOS JÚNIOR, Paulo Jonas dos et al. Liturgia e Culto no primeiro século da Igreja Cristã. Tear Online, São Leopoldo, v. 7, n. 2, p. 98-107, maio 2019.

SANTOS JÚNIOR, Paulo Jonas dos; ROSA, André Luis da. Experiência religiosa: da Reforma Protestante ao avivamento pentecostal. Encontros Teológicos: Reforma ontem e hoje, Florianópolis, v. 31, n. 2, p.235-252, ago. 2016. Disponível em: <facasc. edu.br>. Acesso em: 05 dez. 2020.

SILVA, Edeson dos Anjos; SANTOS, Silvana Duarte Gonçalves dos; SANTOS JÚNIOR, Paulo Jonas dos; PIROZI, Anízio Antônio. SUSTENTABILIDADE E EDUCAÇÃO AMBIENTAL: um estudo a partir do ensino de química e biologia. Revista Transformar, Itaperuna-Rj, v. 14, n. 1, p. 194-209, set. 2020.

TOWNSEND, Colin; BEGON, Michael; HARPER, John. Fundamentos em Ecologia. 3. ed. Porto Alegre: Artmed, 2010. 